\title{
The orbicularis oculi response after hemispheral
} damage

\author{
A BERARDELLI, N ACCORNERO, G CRUCCU, F FABIANO, V GUERRISI, \\ M MANFREDI \\ From the Laboratorio di Neurofisiologia, V Clinica Neurologica and Servizio di Neuroradiologia, \\ Dipartimento di Scienze Neurologiche, Università di Roma "La Sapienza", Italy
}

SUMMARY The corneal and blink reflexes were evaluated in 20 normal subjects and in 30 patients with motor deficits secondary to unilateral hemispheral lesions of vascular origin. In the normal population there were no differences between subjects below and subjects above 50 years of age. In the patients the reflex evoked by electrical stimulation of the cornea of the clinically affected side was depressed in 24 out of 30 cases. The depression mainly affected the afferent branch of the circuit, which triggers both homolateral and contralateral orbicularis oculi discharge (afferent abnormality). In three cases the depression was exerted concomitantly on the efferent branch (afferent and efferent abnormality) and only in one case was it limited to the efferent branch (efferent abnormality). The late R2 component of the blink reflex was depressed in 15 out of 30 patients. The early R1 component was slightly facilitated on the affected side. The changes of the corneal reflex and of the R2 component of blink reflex were similar, but the blink reflex had a greater safety factor.

The patients with an abnormal corneal reflex had more extensive damage than had the patients with normal corneal response, as shown by computer tomography, but the site of the lesion was comparable in the two groups. Conduction through the brain stem circuits mediating the orbicularis oculi response is normally under pyramidal facilitatory influences while facial motoneurons are subjected to pyramidal inhibition. After pyramidal damage the transmission of impulses in the brain stem was slowed down, ultimately to a degree that abolished the reflex. Removal of pyramidal inhibition on facial motoneurons is probably the basis of the slight facilitation of the $\mathrm{R} 1$ component of the blink reflex.

Several authors ${ }^{1-4}$ have observed a depression of the corneal reflex evoked from the eye contralateral to an hemispheral lesion, but Magladery and Teasdall, ${ }^{5}$ using electromyographic recordings, reported that the latency of the reflex was only slightly increased after a unilateral hemispheral lesion. More recently Ongerboer de Visser ${ }^{6}$ observed that the electromyographic response was reduced in most of the patients with unilateral cerebral lesions.

The blink reflex evoked by electrical stimulation of the supraorbital nerve also has been investigated.

Address for reprint requests: Prof. Mario Manfredi, V Clinica Neurologica, Università di Roma, Viale dell'Università, 3000185 - Roma.

Received 12 November 1982 and in revised form 12 March 1983 Accepted 16 April 1983
Both direct and consensual R2 components elicited from the paretic side are depressed according to Messina and Quattrone, ${ }^{7}$ Kimura $^{8}$ and Fisher et al, ${ }^{9}$ while Dehen $e a^{10}{ }^{10}$ found that R2 was depressed on the affected side and facilitated on the normal one, whether evoked from the normal or the paretic side. The homolateral $\cdot R 1$ component was augmented on the paretic side according to Messina and Quattrone $^{7}$ while was unaffected in the population studied by Kimura. ${ }^{8}$ Fisher et $\mathrm{al}^{9}$ reported that the $\mathrm{R} 1$ was delayed during the early phase after a stroke.

In the present study we compared the behaviour of the orbicularis oculi response (corneal reflex and blink reflex to supraorbital nerve stimulation) in a group of patients with unilateral hemispheral lesions and in normal controls. The corneal reflex has been elicited by mechanical stimuli and by electrical 837 
stimulation of the cornea, a method which provides quantification of threshold, latency, amplitude and duration of the response. ${ }^{11}{ }^{12} \mathrm{~A}$ correlation has been attempted with the clinical signs and with the site of the lesion with the aid of computed tomography. Preliminary results have been reported elsewhere. ${ }^{1314}$

\section{Materials and methods}

The study was done in 20 normal volunteers and 30 patients. The normal population consisted of 10 subjects aged from 20 to 50 years (mean age $31.5 \pm 7.46$ years) and 10 subjects matched for age to the patients (age 50 to 70 years, mean age $57 \cdot 1 \pm 8 \cdot 8$ years). The patients, aged from 52 to 70 years (mean age $59.8 \pm 7.8$ years), had a motor deficit following a hemispheric lesion of vascular origin, occurred one to 12 months before examination. None had signs of brain stem damage, deficits of fifth or seventh nerves of peripheral origin, nor disturbances of consciousness at the moment of examination. Computed tomography (CT), was performed with a Siretom 2000 apparatus with a $256 \times 256$ pixel matrix, within one week of the electrophysiological and clinical investigation.

Electrical stimulation of the cornea ${ }^{1112}$ was accomplished with a cotton thread emerging from pipette filled with saline, and manually kept upon the cornea. The pipette was connected with the cathode of a Grass S88 stimulator with a constant current unit CCU 1A. The reference electrode was placed on the forearm or earlobe. The electromyographic (EMG) activity of orbicularis oculi muscles was recorded bipolarly with cup electrodes placed on the inferior lids. The EMG signals were displayed on a OTE Neuroaverager oscilloscope triggered by the stimulus (band width 0.1-3 KHz), and plotted on a Philips PM 8041 xy Plotter. Square pulses of $1 \mathrm{~ms}$ duration, 50-2000 $\mu \mathrm{A}$ were delivered manually, paying attention to spontaneous blinking. The threshold of the reflex was established by determining the weakest stimulus which evoked an EMG response equal or greater than $5.5 \mu \mathrm{V}$. Tolerance-level stimulation was established by determining the strongest stimulus that the subject could bear with reasonable discomfort. The latency of the response was calculated from the stimulus artifact to the first EMG deflection having an amplitude equal or greater than $5.5 \mu \mathrm{V}$. The same criterion was applied for measuring the duration of the response. Amplitude was measured peak to peak. The latency measurement was taken at threshold and tolerance-level stimulation; this last value proved to be reproducible and was currently used for evaluating the results. Amplitude and duration measurements were taken at tolerance-level stimulation. Habituation of the reflex was prevented by low rate ( 5 to 10 per minute) and by unpredictable timing of stimulation.

Mechanical stimulation of the cornea was performed with cotton wisps or air puffs from an electrically operated pump $^{15}$ and evaluated clinically or electromyographically.

The blink reflex was elicited percutaneously with bipolar stimulation of the skin overlying the supraorbital nerve. Stimuli of $1 \mathrm{~ms}$ duration, $10-120 \mathrm{~V}$ were used. Measurement of latency, amplitude and duration of the responses were made at tolerance-level stimulation (usually 3-4 times the threshold), using the same criteria as for the electrically evoked corneal reflex.

Statistical analysis of the results was made with the Student $t$ test and with the analysis of variance ( $F$ test). Differences were considered significant when $\mathrm{p}<0 \cdot 01$.

\section{Results}

\section{Normal subjects}

Electrical stimulation of the cornea evoked a bilateral twitch of the orbicularis oculi similar to the response already described in our laboratory. 1112 There were no differences between subjects below and above 50 years (table 1). The difference in latency between the two direct responses never exceeded $8 \mathrm{~ms}$; the difference between direct and consensual response never exceeded 5 ms. Mechani-

Table 1 Electrically evoked corneal reflex in 20 normal subjects

\begin{tabular}{|c|c|c|c|c|}
\hline & \multicolumn{2}{|c|}{ Subjects below 50 years $(10)$} & \multicolumn{2}{|c|}{ Subjects above 50 years (10) } \\
\hline & Direct & Consensual & Direct & Consensual \\
\hline $\begin{array}{l}\text { Threshold } \mu \mathrm{A} \\
\text { Latency in } \mathrm{ms} \text { (at threshold stimulation) } \\
\text { Latency in } \mathrm{ms} \text { (at tolerance level stimulation) } \\
\text { Amplitude } \mu \mathrm{V} \\
\text { Duration in } \mathrm{ms}\end{array}$ & $\begin{aligned} 54 \cdot 4 & \pm 7 \cdot 4 \\
39 \cdot 3 & \pm 3 \cdot 3 \\
300 & \pm 74 \cdot 5 \\
107 \cdot 1 & \pm 49\end{aligned}$ & $\begin{array}{l}88 \cdot 4 \\
57 \cdot 4 \pm 7 \\
41 \cdot 3 \pm 3 \cdot 5 \\
265 \pm 81 \cdot 9 \\
106 \cdot 4 \pm 50\end{array}$ & $\begin{array}{l}58 \quad 218 \pm \\
40.8 \cdot 34 \\
40 \cdot 8 \pm 3 \cdot 3 \\
306 \pm 86 \\
102 \cdot 5 \pm 38 \cdot 5\end{array}$ & $\begin{array}{r}5 \cdot 1 \\
62 \cdot 10 \pm 6 \cdot 2 \\
43 \cdot 7 \pm 2 \cdot 7 \\
256 \cdot 5 \pm 86 \cdot 5 \\
98 \cdot 8 \pm 38\end{array}$ \\
\hline
\end{tabular}

Table 2 Blink reflex in 20 normal subjects

\begin{tabular}{|c|c|c|c|c|c|c|}
\hline & \multicolumn{3}{|c|}{ Subjects below 50 years $(10)$} & \multicolumn{3}{|c|}{ Subjects above 50 years (10) } \\
\hline & $\boldsymbol{R I}$ & $R 2$ (Direct) & $R 2$ (Consensual) & $R \mathbf{R}$ & $R 2$ (Direct) & $R 2$ (Consensual) \\
\hline $\begin{array}{l}\text { Latency in ms } \\
\text { Amplitude } \mu \mathrm{V} \\
\text { Duration } \mathrm{ms}\end{array}$ & $\begin{array}{r}11.9 \pm 0.5 \\
330 \pm 90.7 \\
-\end{array}$ & $\begin{array}{cl}32 \cdot 2 & \pm 2.6 \\
340 & \pm 84 \\
71 & \pm 23.7\end{array}$ & $\begin{array}{rr}34.2 & \pm 2.1 \\
325 & \pm 67.7 \\
70 & \pm 22.9\end{array}$ & $\begin{array}{l}10 \cdot 9 \pm 1.4 \\
230 \pm 70\end{array}$ & $\begin{array}{l}32.5 \pm 3.6 \\
360 \pm 78.3 \\
82.5 \pm 36\end{array}$ & $\begin{aligned} 34 \cdot 3 & \pm 3 \cdot 4 \\
314 & \pm 69 \\
82 & \pm 36\end{aligned}$ \\
\hline
\end{tabular}


Table 3 Orbicularis oculi response from non paretic side of 30 patients

\begin{tabular}{|c|c|c|c|}
\hline \multicolumn{2}{|l|}{$\boldsymbol{A}$} & \multicolumn{2}{|l|}{$\boldsymbol{B}$} \\
\hline \multicolumn{2}{|c|}{ Direct response of the corneal reflex } & \multicolumn{2}{|c|}{ Direct response of the blink reflex } \\
\hline $\begin{array}{l}\text { Threshold } \\
\text { Latency (at threshold) } \\
\text { Latency (at tolerance-level) } \\
\text { Amplitude } \\
\text { Duration }\end{array}$ & $\begin{aligned} 213 & \pm 70 \\
56 & \pm 5 \cdot 2 \\
41 \cdot 3 & \pm 4 \\
270 & \pm 130 \\
89 \cdot 7 & \pm 65\end{aligned}$ & $\begin{array}{l}\mathbf{R}_{1} \text { latency } \\
\mathbf{R}_{1} \text { amplitude } \\
\mathbf{R}_{2} \text { latency } \\
\mathbf{R}_{2} \text { amplitude } \\
\mathbf{R}_{2} \text { duration }\end{array}$ & $\begin{aligned} 10.7 & \pm 1 \cdot 53 \\
169 & \pm 137 \\
34 & \pm 3.93 \\
251 & \pm 121 \\
69 \cdot 8 & \pm 44\end{aligned}$ \\
\hline
\end{tabular}

cal stimuli evoked a bilateral response in all the subjects.

The early homolateral response (R1) and the late bilateral twitch (R2) of the blink reflex to supraorbital nerve stimulation were similar in the two groups of subjects (table 2) and in line with data in the literature. ${ }^{81617}$

\section{Patients: non paretic side}

The direct response elicited by electrical stimulation of the cornea of the non paretic side was normal in all patients (table 3 ). The consensual response was normal except in four patients, who showed increased latency and decreased amplitude and duration (see next section). The mechanical stimulation of the cornea elicited a bilateral twitch of normal aspect in all patients. The $R 1$ response and the direct component of the $\mathrm{R} 2$ response of the blink reflex to supraorbital nerve stimulation were normal (table 3). The consensual R2 component was normal except in two patients, who showed increased latency and decreased amplitude and duration (see next section).

\section{Patients: paretic side}

The electrical stimulation of the cornea of the paretic side elicited a normal response in six patients. In the remaining 24 the reflex showed abnormalities of the afferent branch (20 patients), the efferent branch (one patient) or both (three patients).

Afferent abnormalities were constituted by: (1) inability of the electrical stimulus to elicit the reflex, even at intensities 10 times the threshold of the non paretic side (three patients); (2) increased latency of direct and consensual response (14 patients, table 4), (fig 1); (3) increased threshold of the reflex (three patients). A comparable increase was also present in five of the 14 patients with increased latency of the response. The threshold augmentation ranged from 50 to $1000 \mu \mathrm{A}$ (mean $712 \pm 264 \mu \mathrm{A}$ ).

Efferent abnormality was present in one patient who showed a delayed direct response stimulating the affected side (48 ms direct; $42 \mathrm{~ms}$ consensual) and a delayed consensual response on stimulation on the non paretic side ( $52 \mathrm{~ms}$ consensual; $42 \mathrm{~ms}$ direct). The threshold was normal. The consensual response on stimulation of the paretic side was unaffected.

Afferent and efferent abnormality was present in three patients and constituted by an increased latency of direct and consensual responses (mean $51 \cdot 5 \pm 2.1 \mathrm{~ms}$ for direct and $52 \pm 2.2 \mathrm{~ms}$ for consensual response); in two of them the threshold was also augmented (range 500-1000 $\mu \mathrm{A}$ ). In the same subjects the stimulation of the non paretic side elicited a delayed consensual response (mean $55.5 \pm 3.5 \mathrm{~ms}$ ).

Modifications of amplitude and duration followed inversely threshold and latency changes, but were a less sensitive measure. The same behaviour was observed in patients with trigeminal damage. ${ }^{11} 12$

The reflex evoked by mechanical stimulation of the cornea showed no differences with stimulation of the non paretic side in 21 patients. It was absent in the three patients without response to electrical stimulation and reduced in six other patients, all belonging to the group of patients with the afferent type of abnormality on electrical corneal stimulation.

The blink reflex to supraorbital nerve stimulation was present in all patients. The bilateral $R 2$ component was normal in 15 cases. In 13 patients the response was bilaterally delayed (mean $42 \cdot 2 \pm 4 \cdot 2$ $\mathrm{ms}$ for direct and $43.7 \pm 4.2 \mathrm{~ms}$ for consensual response) (afferent abnormality). One patient showed a delay of the direct response with stimulation of the paretic side ( $35 \mathrm{~ms}$ direct; 30 ms consen-

Table 4 Latency of corneal reflex in 14 patients with afferent abnormality

\begin{tabular}{|c|c|c|c|c|}
\hline & \multicolumn{2}{|c|}{ Non paretic side } & \multicolumn{2}{|l|}{ Paretic side } \\
\hline & Direct & Consensual & Direct & Consensual \\
\hline $\begin{array}{l}\text { Threshold stimulation } \\
\text { Tolerance-level stimulation }\end{array}$ & $\begin{array}{l}57.8 \pm 3.9 \\
40.7 \pm 3.7\end{array}$ & $\begin{array}{l}60.4 \pm 4.2 \\
42.6 \pm 3.6\end{array}$ & $\begin{array}{l}67.6 \pm 2.5 \\
55.8 \pm 5.8\end{array}$ & $\begin{array}{l}68.4 \pm 2.4 \\
57 \cdot 3 \pm 5 \cdot 8\end{array}$ \\
\hline
\end{tabular}

The difference between normal and affected side are statistically significant $(p<0.01)$. 


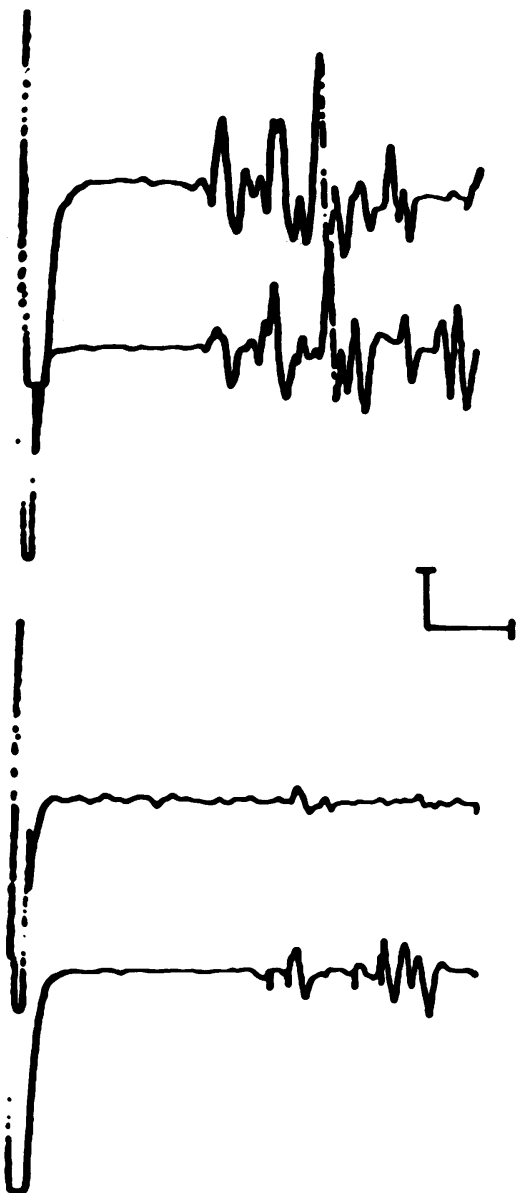

Fig 1 Orbicularis oculi response evoked by electrical stimulation of the cornea. (top) Reflex evoked by stimulation of the nonparetic side. The direct and consensual response are normal. (bottom) Reflex evoked by stimulation of the hemiparetic side. The direct and consensual response are delayed in latency and decreased in amplitude. Calibration: $0.1 \mathrm{mV}, 20 \mathrm{~ms}$.

sual) and of the consensual response with stimulation of the non paretic side $(40 \mathrm{~ms}$ consensual; 30 $\mathrm{ms}$ direct) (efferent abnormality). In one patient the response was bilaterally delayed on stimulation of the paretic side $(43 \mathrm{~ms}$ for direct and $45 \mathrm{~ms}$ for consensual response) and consensually delayed on

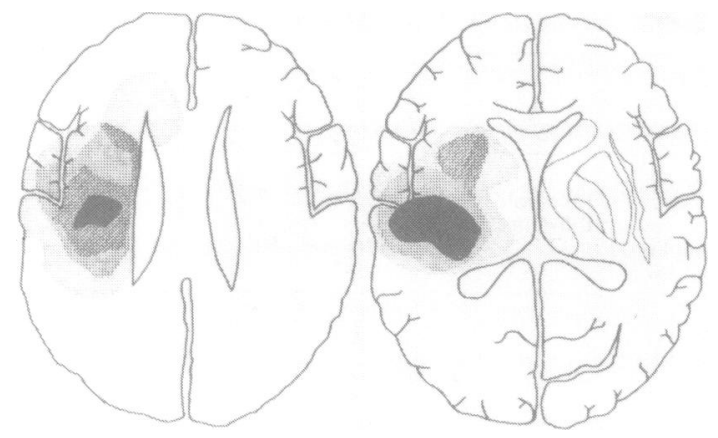

Fig 2 Composite of lesions of subjects with normal corneal reflex.

stimulation of the non paretic side $(48 \mathrm{~ms})$ (afferent and efferent abnormality). The modification of the R2 component appeared in patients showing the same type of abnormality on electrical stimulation of the cornea and were accompanied by a reduction of amplitude and duration of the discharge.

The homolateral R1 component of the response was present in all patients, and appeared slightly facilitated with respect to non paretic side. The latency was decreased (mean 10.1 $\pm 1.44 \mathrm{~ms}$ ) and the amplitude increased (mean 194.2 $\pm 122.5 \mu \mathrm{V}$ ) but neither individual nor mean changes were significant.

\section{Clinical and CT findings}

All the patients showed a unilateral motor deficit, which was a hemiplegia in 13 cases and hemiparesis in 17 cases. The depression of the orbicularis oculi response was proportional to the degree of motor deficit (table 5). A superficial and/or proprioceptive defect anaesthesia or hypoesthesia was present in 16 patients. Sensory signs were not predictive of the abnormality of the response.

The cerebral lesions were localised by CT scan, and mapped at two different levels (figs 2,3 ). There was no difference in the site of the lesion between patients with normal and with abnormal reflexes, a finding in line with modality of selection of patients, all affected by a motor deficit of central origin. As expected, the patients with normal orbicularis oculi response (and with a minor degree of motor deficit) had smaller lesions.

Table 5 Direct response of the corneal reflex in patients with hemiparesis and hemiplegia

\begin{tabular}{lll}
\hline & Patients with hemiparesis (17) & Patients with hemiplegia (13) \\
\hline Threshold in $\mu \mathrm{A}$ & $400 \pm 270 \cdot 9$ & $467 \pm 270 \cdot 8$ \\
Latency in $\mathrm{ms}$ (at threshold stimulation) & $61 \cdot 38 \pm 6 \cdot 22$ & $64 \cdot 5 \pm 7.6$ \\
Latency in $\mathrm{ms}$ (at tolerance level stimulation) & $46.47 \pm 6.52^{*}$ & $53.1 \pm 9^{*}$ \\
\hline
\end{tabular}

${ }^{*}$ Statistically significant differences $(p<0.05)$. 


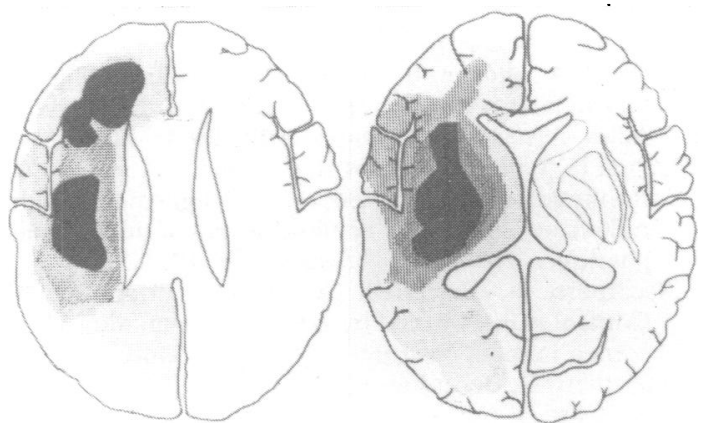

Fig 3 Composite of lesions of subjects with abnormal corneal reflex.

\section{Discussion}

The orbicularis oculi response evoked by electrical stimulation of the cornea was not modified in normal subjects above 50 years as compared with younger age groups. There were no consistent modifications on the non paretic side of patients with unilateral hemispheral lesions. Conversely, it was significantly depressed on the paretic side in 24 out of 30 patients. The most sensitive measures were latency at tolerance-level stimulation and threshold. The changes of the mechanically evoked reflex could be less easily quantified. Even with sophisticated methods of mechanical stimulation 56151819 the latency range is larger than with electrical stimuli. ${ }^{12}$ In addition, the threshold of the reflex cannot be graded.

The late (R2) component of the blink reflex to supraorbital nerve stimulation was less sensitive than the corneal reflex, and was depressed in 15 out of 30 patients. This component can be equated to the corneal reflex ${ }^{8182021}$ and shares the same intrinsic trigemino-facial connections. ${ }^{22}{ }^{23}$ However, it is conducted by a large fibre bundle of the supraorbital nerve compared to the small bundle of the ciliary nerve mediating corneal sensation. Consequently, it possesses a greater safety factor. In fact, the blink reflex could be obtained from all patients, including the three cases without response to corneal stimulation.

The depression of orbicularis oculi response observed in our patients confirms the clinical observations of Gardner, ${ }^{1}$ Walker, ${ }^{2}$ Oliver,${ }^{3}$ Ross, ${ }^{4}$ and the electrophysiological findings of Magladery and Teasdall, ${ }^{5}$ Messina and Quattrone, ${ }^{7}$ Kimura, ${ }^{8}$ Fisher et $a l^{9}$ and Ongerboer de Visser. ${ }^{6}$ Contrarily to the finding of Dehen et $a^{10}$ the consensual response was rarely unaffected, but never facilitated.

Ongerboer de Visser and co-workers ${ }^{22} 23$ from the study of patients with brain stem and thalamic lesions, concluded that the reflex is conducted via multisynaptic pathways in the lateral reticular formation of the lower brain stem, from the spinal trigeminal nucleus to the ipsilateral and contralateral facial nuclei. The reduction observed after hemispheral lesions, which can abolish the reflex, cannot be attributed to an interruption of the reflex arc which does not reach beyond the pons both in primates $^{22} 23$ and felines. ${ }^{24}$ A lack of facilitating influences from descending pathways must be involved. Facilitatory influences are likely to be mediated by fibres running with pyramidal tracts since the inhibition takes place after pyramidal lesions and is proportional to the pyramidal defect. Pyramidal projections to the spinal trigeminal nucleus have been described in primates, ${ }^{25-27}$ and their facilitatory role on sensory transmission has been demonstrated in felines. ${ }^{25}$ We have been unable to confirm the conclusion of Ongerboer de Visser ${ }^{6}$ that the lower post-central region is the critical zone of origin of the descending facilitatory projections. In our experience damage in this region is not predictive of an abnormal response on electrical corneal stimulation since the lower post-central region was damaged in 16 out of 24 patients with abnormal responses and in five out of six with normal findings.

In normal subjects, the latency of the orbicularis oculi response fell noticeably by simply increasing the stimulation strength (see table 1). This reduction can be largely attributed to shorter temporal summation within the polysynaptic neuronal nets of the reticular formation of the lower brain stem, and/or to short circuiting in the same pathway. After pyramidal damage, the latency reduction which follows the increase of stimulation strength is defective on the paretic side. In the patients with afferent delay, the mean latency gain between direct responses obtained at threshold and at tolerancelevel stimulation is $17 \cdot 1 \mathrm{~ms}$ on the non paretic side, and $11.8 \mathrm{~ms}$ on the paretic side (table 4 ). The corresponding values for the consensual response are 17.8 and $11.1 \mathrm{~ms}$. It therefore seems likely that, on the paretic side, the circuit involves a larger number of synapses and/or necessitates of a more prolonged afferent barrage. Also, the mechanisms which are, in normal subjects and on the non paretic side of pyramidal patients, the basis of the latency gain with tolerance-level stimulation, are less efficient on the side contralateral to a pyramidal lesion.

The conduction through the brain stem net mediating the corneal reflex seems therefore under the control of descending facilitatory influences. In the absence of these, the circuit is slowed, ultimately to a degree resulting in its functional interruption. A similar condition may take place in coma without structural damage of the brain stem, a condition in 
which the orbicularis oculi response gives a reliable measure of cortical depression. ${ }^{29}$ The depression is mainly exerted on the afferent branch of the circuit, which triggers both homolateral and contralateral orbicularis oculi discharge. In a minority of patients, an inhibitory effect was exerted concomitantly or exclusively on the efferent branch of the circuit. Similar findings were present in the population studied by Ongerboer de Visser. ${ }^{6}$

The inhibitory effects of the pyramidal damage seem to act on the synaptic net converging on the facial motoneurons of the paretic side rather than on facial motoneurons themselves, in view of the behaviour of the R1 component of the blink reflex to supraorbital nerve stimulation. The response is related by the pontine trigeminal nucleus ${ }^{816}$ and mediated by cutaneous afferents. ${ }^{17}$ Its oligosynaptic net $^{30}$ may explain the lack of inhibition of $R 1$ after contralateral hemispheric damage. On the contrary, in accordance with the findings of Messina and Quattrone, ${ }^{7}$ the response was slightly facilitated on the paretic side, as showed by a latency reduction of $0.6 \mathrm{~ms}$ and the small increase in amplitude. This change, though not statistically significant, acquires value in view of the depression of late components. Facial motoneurones may well be subjected to the same inhibitory influences as impinge on spinal motoneurones. Removal of pyramidal inhibition could result in an accelerated efferent discharge.

We are grateful to Mrs Antonella Venditti for typing the manuscript and to Miss Paola Brancaccio for the illustrations. This study was supported by grants from the Consiglio Nazionale delle Ricerche (n. 80.00493.04, n. 81.01830.04), Ministero della Pubblica Istruzione, Università di Roma and Regione Lazio.

\section{References}

1 Gardner WJ. Removal of the right cerebral hemisphere for infiltration glioma. JAMA 1933;101:823-6.

${ }^{2}$ Walker AE. The cerebral arc of the corneal reflex. $J$ Nerv Ment Dis 1949;92:569-78.

${ }^{3}$ Oliver LC. The supranuclear arc of the corneal refiex. Acta Psychiat Scand 1952;27:329-33.

${ }^{4}$ Ross RT. Corneal reflex in hemisphere disease. J Neurol Neurosurg Psychiatry 1972;35:877-80.

${ }^{5}$ Magladery JW, Teasdall RD. Corneal reflexes: an electromyographic study in man. Arch Neurol 1961;5:269-74.

' Ongerboer de Visser BW. Corneal reflex latency in lesions of the lower post-central region. Neurology (NY) 1981;31:701-7.

${ }^{7}$ Messina C, Quattrone A. Comportamento dei riflessi trigemino-facciali in soggetti con lesioni emisferiche. Riv Neurol 1973;43:379-86.

${ }^{8}$ Kimura J. Effect of hemispheral lesions on the contralat- eral blink reflex. A clinical study. Neurology (Minneap) 1974;24:168-74.

${ }^{9}$ Fisher MA, Shahani BI, Young RR. Assessing segmental excitability after acute rostral lesions: II. The blink reflex. Neurology (Minneap) 1979;29:45-50.

${ }^{10}$ Dehen H, Willer J, Bathien N, Cambier J. Analyse electrophysiologique du reflexe de clignement (blink reflex) au cours de l'hemiplegie par lesions hemispheriques. Rev Neurol (Paris) 1975;131:85-94.

$"$ Accornero N, Berardelli A, Bini G, Manfredi M. Corneal reflex evoked by electrical stimulation of the cornea in man. Neurosci Lett 1978;1:S340.

${ }^{12}$ Accornero N, Berardelli A, Bini G, Cruccu G, Manfredi M. Corneal reflex elicited by electrical stimulation of the human cornea. Neurology (Minneap) 1980;30:782-5.

${ }^{13}$ Berardelli A, Accornero N, Bini G, et al. Studio del riflesso corneale mediante stimolazione elettrica della cornea in soggetti con lesioni emisferiche di origine vascolare: risultati preliminari. Riv Ital EEG Clin Neurofisiol 1980;3:213-8.

${ }^{14}$ Berardelli A, Accornero N, Bini G, et al.Corneal reflex evoked by electrical stimulation in patients with hemispheric lesions. Electroencephalogr Clin Neurophysiol 1981;51:64.

15 Accornero N, Berardelli A, Bini G, Cruccu G, Caruso R, Noletti A. Metodo di registrazione del riflesso corneale nell'uomo mediante stimolazione fisiologica. Boll Soc Ital Biol Sper 1978;54:249-51.

${ }^{16}$ Kimura J. Electrically elicited blink reflex in diagnosis of multiple sclerosis-review of 260 patients over a seven year period. Brain 1975;98:413-26.

${ }^{17}$ Shahani BT, Young RR. Human orbicularis oculi reflexes. Neurology (Minneap) 1972;22:149-54.

18 Thatcher DB, Van Allen MW. Corneal reflex latency. Neurology (Minneap) 1971;21:735-7.

${ }^{19}$ Ongerboer de Visser BW, Melchelse K, Megens HA. Corneal reflex latency in trigeminal nerve lesions. Neurology (Minneap) 1977;27:1164-7.

${ }^{20}$ Kugelberg E. Facial reflexes. Brain 1952;75:385-96.

${ }^{21}$ Rushworth G. Observations on blink reflexes. J Neurol Neurosurg Psychiatry 1962;25:93-108.

${ }^{22}$ Ongerboer de Visser BW, Kuypers HGJM. Late blink reflex changes in lateral medullary lesions. An electrophysiological and neuro-anatomical study of Wallenberg's syndrome. Brain 1978;101:285-94.

${ }^{23}$ Ongerboer de Visser BW, Moffie D. Effects of brain stem and thalamic lesions on the corneal reflex: an electrophysiological and anatomical study. Brain 1979;102:595-608.

${ }^{24}$ Hiraoka M, Shimamura M. Neural mechanisms of the corneal blinking reflex in cats. Brain Res 1977;125:265-75.

${ }^{25}$ Kuypers HGJM. Central cortical projections to motor and somatosensory cell-groups. An experimental study in the rhesus monkey. Brain 1960;83:161-84.

${ }^{26}$ Jones EG, Wise SP. Size, laminal and columnar distribution of efferent cells in the sensorimotor cortex of monkeys. J Comp Neurol 1977;175:391-438.

${ }^{27}$ Brodal P. The cortico-pontine projections in the rhesus monkey. Origin and principles of organization. Brain 1978;101:251-84.

${ }^{28}$ Wiesendanger M, Felix D. Pyramidal excitation of 
lemniscal neurons and facilitation of sensory transmission in the spinal trigeminal nucleus of the cat. Exp Neurol 1969;25:1-17.

${ }^{29}$ Lyon LW, Kimura J, McCormick WF. Orbicularis oculi reflex in coma: clinical, electrophysiological and pathological correlations. J Neurol Neurosurg
Psychiatry 1972;35:582-98.

${ }^{30}$ Trontelj MA, Trontelj JV. Reflex arc of the first component of the human blink reflex: a single motoneurone study. J Neurol Neurosurg Psychiatry 1978;41:538-48. 